\title{
HUBUNGAN PENGETAHUAN DAN MOTIVASI SUAMI AKSEPTOR KB SUNTIK DEPO MEDROKSI PROGESTERONE ASETAT (DMPA) DENGAN KEPATUHAN KUNJUNGAN ULANG DI KLINIK BIDAN N. LUMBANGAOL DESA SIMANGARONSANG KECEMATAN DOLOKSANGGUL TAHUN 2018
}

\author{
Winta Mariana Batubara ${ }^{1}$, Fransiska Debataraja ${ }^{2}$ \\ STIKes Kesehatan Baru, Indonesia
}

\section{Article Info \\ Article history: \\ Received Des 08, 2020 \\ Revised Mar 06, 2021 \\ Accepted Mar 13, 2021}

\section{Keywords:}

Knowledge

Husband's Motivation

Compliance Repeat Visit

\begin{abstract}
Injection contraception is a contraceptive that is injected into the body for a certain period of time, then enters the blood vessels absorbed little by little by the body which is useful to prevent pregnancy. This study was to determine the relationship of knowledge and motivation of the husband of the mother of DMPA KB acceptors with the compliance of the re-visit of the clinic of the simangaronsang village midwife. With this type of research using descriptive cross-sectional design analysis with chi square test and sampling technique using random sampling method with a total sample of 58 respondents with analysis of univariate analysis data and bivariate analysis. The results showed that there was a relationship of knowledge with compliance with repeat visits where df: 2 was obtained obtained $\mathrm{X}^{2}$ count (30.644) $>\mathrm{X}^{2}$ table (5.591), the husband's motivation was related to repeated visit compliance where df: 2 obtained $X^{2}$ count (13.469) > $X^{2}$ table (5.591), and the source of information is related to the compliance of repeat visits where df: 2 obtained $\mathrm{X}^{2}$ count $(8.028)>\mathrm{X}^{2}$ table (5.591). It is expected that the respondent will increase the knowledge and motivation of the husband in increasing the respondent's compliance in conducting a repeat visit so as to improve family welfare.
\end{abstract}

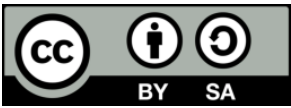

\section{Corresponding Author:}

Winta Mariana Batubara, DIII Keperawatan, STIKes Kesehatan Baru JL. Bukit Sipalakki, Kecamatan Doloksanggul, Kabupaten Humbang Hasundutan, Sumatera Utara. Email: winta.batubara@stikeskb.ac.id

\section{INTRODUCTION}

Pertumbuhan penduduk yang semakin meningkat dapat mengakibatkan kepadatan penduduk sehingga turunnya kesejahteraan bangsa yangterdiri dari keluarga kecil yaitu ayah, ibu dan anak. Kesejahteraan ibu dan anak juga dipengaruhi dari proses kehamilan, persalinan, nifas, neonatus dan juga pemakaian alat kontrasepsi ${ }^{1}$.

Salah satu keikutsertaan pemerintah dalam meningkatkan pelayanan KByang bekerja sama dengan BKKBN yaitu menyediakan tempat pelayanan KB seperti praktek bidan mandiri, pelayanan KB gratis dari puskesmas, membuat program Kampung KB ke desa-desa. Fasilitas KB ini memiliki proporsi yang sangat besar $(52,43 \%)$. Sedangkan fasilitas KB milik pemerintah memiliki persentase sebesar 16,66\%. Pemerintah 
melalui BKKBN dan Kementerian Kesehatan bertanggungjawab terhadap semua jenis fasilitas KB tersebut, tidak hanya kepada fasilitas KB milik pemerintah saja. Hal ini merupakan salah satu tantangan yang dihadapi dalam implementasi program $\mathrm{KB}^{2}$.

Presiden Joko Widodo (Jokowi) pada 27 Februari 2017 lalu, telah menandatangani Instruksi Presiden (Inpres) Nomor 1 Tahun 2017 tentang Gerakan Masyarakat Hidup Sehat.Pertama, menetapkan kebijakan dan mengambil langkah-langkah sesuai tugas, fungsi, dan kewenangan masing-masing untuk mewujudkan Gerakan Masyarakat Hidup Sehat, yaitu: 1. Peningkatan aktivitas fisik; 2. Peningkatan perilaku hidup sehat; 3. Penyediaan pangan sehat dan percepatan perbaikan gizi; 4. Peningkatan pencegahan dan deteksi dini penyakit; 5. Peningkatan kualitas lingkungan; dan 6. Peningkatan edukasi hidup sehat ${ }^{3}$.

Berdasarkan survey penelitian yang dilakukan di klinik bidan N.Lumbangaol desa Simangaronsang telah di dapat sebanyak 300 orang PUS dan 150 orang yang menggunakan kontrasepsi, dimana 10 orang menggunakan KB suntik 1 bulan dan 140 orang yang menggunakan KB suntik 3 bulan. Dan pada saat survey awal dari 2 orang responden yang di jumpai responden mengatakan bahwa responden tidak ingat untuk melakukan kunjungan ulang di karenakan pekerjaan yang tidak bisa di tinggalkan dan lupa untuk tanggal kembalinnya kunjungan ulang.

\section{RESEARCH METHOD}

Jenis penelitian ini adalah kuantatif Penelitian ini merupakan studi analitik deskriptif dengan pendekatan Cross Sectional. Dimana seluruh variabel independen dan variabel dependen di ukur pada saat yang sama pada saat penelitian berlangsung yang dilaksanakan dengan menggunakan kuesioner untuk mengetahui Hubungan Pengetahuan dan motivasi suami akseptor KB Suntik DMPA dengan kepatuhan kunjungan ulang di desa Simanngaronsang kecamatan Doloksanggul kabupaten Humbang Hasundutan tahun 2018.

Populasi dalam penelitian ini adalah keseluruhan unit analisi yang karakteristiknya diduga menjadi sampel. Pada penelitian ini, yang menjadi populasi nya adalah semua ibu yang menggunakan KB suntik DMPA sebanyak 140 orang di desa simangaronsang pada saat survey awal. Tehnik pengambilan sampel dalam penelitian ini adalah total random sampling (pengambilan sampel secara acak). Sampel dalam penelitian ini adalah sebagian ibu yang menggunakan KB suntik DMPA di desa Simangaronsang sebanyak 58 orang.

\section{RESULTS AND ANALYSIS}

\subsection{Hasil}

\section{Analisa Univariat}

Analisa univariat dilakukan untuk menggambarkan penyajian data dari beberapa variabel dalam bentuk tabel distribusi frekuensi. Adapun hasil pengumpulan data yang dikumpulkan melalui kuisioner yang dibagi dengan responden.

Tabel 1. Distribusi Frekuensi Pengetahuan, Motivasi Suami dan Sumber Informasi Akseptor KB Suntik DMPA dengan Kepatuhan Kunjungan Ulang Bidan N. Lumbangaol Desa Simangaronsang Kecamatan Doloksanggul Kabupaten Humbang Hasundutan Tahun 2018

\begin{tabular}{|c|c|c|c|}
\hline No & variabel & Jumlah & Persentase $(\%)$ \\
\hline \multirow[t]{5}{*}{$\mathbf{1}$} & Pengetahuan & & \\
\hline & a. Baik & 36 orang & $62,1 \%$ \\
\hline & b. Cukup & 15 orang & $25,9 \%$ \\
\hline & c. Kurang & 7 orang & $12,1 \%$ \\
\hline & Total & 58 orang & $100 \%$ \\
\hline \multirow[t]{5}{*}{2} & Motivasi Suami & & \\
\hline & a. Baik & 25 orang & $43,1 \%$ \\
\hline & b. $\quad$ Cukup & 26 orang & $44,8 \%$ \\
\hline & c. Kurang & 7 orang & $12,1 \%$ \\
\hline & Total & 58 orang & $100 \%$ \\
\hline \multirow[t]{5}{*}{3} & Sumber Informasi & & \\
\hline & a. Tenaga kesehatan & 36 orang & $62,1 \%$ \\
\hline & b. Media elektronik & 20 orang & $34,5 \%$ \\
\hline & c. Media cetak & 2 orang & $3,4 \%$ \\
\hline & Total & 58 orang & $100 \%$ \\
\hline \multirow[t]{4}{*}{4} & Kepatuhan kunjungan ulang & & \\
\hline & a. Patuh & 46 orang & $79,3 \%$ \\
\hline & b. Tidak patuh & 12 orang & $20,7 \%$ \\
\hline & Total & 58 orang & $100 \%$ \\
\hline
\end{tabular}


Dari tabel 1 di atas dapat dilihat bahwa pengetahuan ibu tentang kepatuhan kunjungan ulang dari 58 responden yang berpengetahuan baik sebanyak 36 orang $(62,1 \%)$. Dan yang berpengetahuan cukup sebanyak 15 orang $(25,9 \%)$ dan yang berpengetahuan kurang sebanyak 7 orang $(12,1 \%)$. Berdasarkan variabel motivasi suami kategori baik sebanyak 25 orang $(43,1 \%)$ dan kategori cukup sebanyak 26 orang $(44,8 \%)$ dan kategori kurang sebanyak7 orang $(12,1 \%)$. Berdasarkan variabel sumber informasi yang diperoleh ibu dari tenaga kesehatan sebanyak 36 orang $(62,1 \%)$. Dan sumber informasi yang diperoleh ibu dari Media Elektronik sebanyak 20 orang (34,5\%). Dan sumber informasi berasal dari media cetak sebanyak 2 orang $(12,1 \%)$.

\section{Analisa Bivariat}

Setelah diketahui variabel, maka dilakukan analisa lebih lanjut berupa analisa bivariat. Data yang didapat dari kedua variabel merupakan data untuk memperoleh distribusi frekuensi yang bertujuan untuk mengetahui Pengetahuan Dan Motivasi Suami Ibu Akseptor KB Suntik DMPA Dengan Kepatuhan Kunjungan Ulang Bidan N.Lumbangaol Desa Simangaronsang Kecamatan Doloksanggul Kabupaten Humbang Hasundutan Tahun 2018.

Tabel 2. Distribusi Frekuensi Pengetahuan Responden Tentang Kepatuhan Kunjungan Ulang Di Klinik Bidan N. Lumbangaol Desa Simangaronsang Kecamatan Doloksanggul Kabupaten Humbang Hasundutan Tahun 2018

\begin{tabular}{|c|c|c|c|c|c|c|c|c|c|}
\hline \multirow[t]{3}{*}{ No } & \multirow[t]{3}{*}{ Pengetahuan } & \multicolumn{6}{|c|}{ Kepatuhan kunjungan ulang } & \multirow[t]{3}{*}{ df } & \multirow[t]{3}{*}{$\mathbf{X}^{2}$} \\
\hline & & \multicolumn{2}{|c|}{ Patuh } & \multicolumn{2}{|c|}{ Tidak patuh } & \multicolumn{2}{|c|}{ Total } & & \\
\hline & & $\mathbf{n}$ & $\%$ & $\mathbf{n}$ & $\%$ & $\mathbf{N}$ & $\%$ & & \\
\hline 1 & Baik & 32 & 88,89 & 4 & 11,11 & 36 & 100 & 2 & 30,644 \\
\hline 2 & Cukup & 14 & 93,33 & 1 & 6,67 & 15 & 100 & & \\
\hline 3 & Kurang & 0 & 0 & 7 & 100 & 7 & 100 & & \\
\hline
\end{tabular}

Berdasarkan tabel 2 diketahui bahwa dari 58 responden ibu yang berpengetahuan baik sebanyak 36 orang $(100 \%)$ mayoritas patuh terhadap kunjungan sebanyak 32 orang $(88,9 \%)$ dan minoritas kategori tidak patuh sebanyak 4 orang $(11,11 \%)$. Pada pengetahuan ibu kategori Cukup sebanyak 15 orang dengan mayoritas patuh terhadap kunjungan ulang sebanyak 14 orang $(93,33 \%)$ dan minoritas tidak patuh sebanyak 1 orang $(6,67 \%)$. Dan pengetahuan kurang sebanyak 7 orang $(100 \%)$ semuanya tidak patuh terhadap kunjungan ulang KB suntik DMPA.

Dengan menggunakan uji chi-square dalam tingkat kepercayaan 95\% ( $\alpha: 0,05)$ dan df: 2 diperoleh $\mathrm{X}^{2}$ hitung $(30,644)>\mathrm{X}^{2}$ tabel $(5,591)$, maka Ha diterima Ho ditolak sehingga ada Hubungan Pengetahuan dengan Kepatuhan Kunjungan Ulang di Klinik Bidan N. Lumbangaol Desa Simangaronsang Kecamatan Doloksanggul Kabupaten Humbang Hasundutan Tahun 2018.

Tabel 3. Distribusi Frekuensi Pengetahuan Responden Menurut Motivasi Suami Tentang Kepatuhan Kunjungan Ulang Di Klinik Bidan N. Lumbangaol Desa Simangaronsang Kecamatan Doloksanggul Kabupaten Humbang Hasundutan Tahun 2018

\begin{tabular}{|c|c|c|c|c|c|c|c|c|c|}
\hline \multirow[t]{3}{*}{ No } & \multirow[t]{3}{*}{ Motivasi suami } & \multicolumn{6}{|c|}{ Kepatuhan Kunjungan Ulang } & \multirow[t]{3}{*}{ df } & \multirow[t]{3}{*}{$\mathbf{X}^{2}$} \\
\hline & & \multicolumn{2}{|c|}{ Patuh } & \multicolumn{2}{|c|}{ Tidak patuh } & \multicolumn{2}{|c|}{ Total } & & \\
\hline & & $\mathbf{n}$ & $\%$ & $\mathbf{n}$ & $\%$ & $\mathbf{N}$ & $\%$ & & \\
\hline 1 & Baik & 23 & 92 & 2 & 8 & 25 & 100,0 & 2 & 13,469 \\
\hline 2 & Cukup & 21 & 80,77 & 5 & 19,23 & 26 & 100,0 & & \\
\hline 3 & Kurang & 2 & 28,58 & 5 & 71,42 & 7 & 100,0 & & \\
\hline
\end{tabular}

Berdasarkan tabel 3 diketahui bahwa dari 58 responden yang motivasi suami kategori baik sebanyak 25 orang mayoritas patuh terhadap kunjungan ulang ibu sebanyak 23 orang (92\%) minoritas kategori tidak patuh sebanyak 2 orang (8\%). Pada motivasi kategori cukup sebanyak 26 orang terdapat mayoritas patuh sebanyak 21 orang $(80,77 \%)$ dan minoritas kategori tidak patuh sebanyak 5 orang $(19,23 \%)$. Dan motivasu suami yang kurang sebanayk 7 orang yang mayoritas kategori tidak patuh sebanyak 5 orang $(71,42 \%)$ dan minoritas patuh sebanyak $2(28,58 \%)$.

Dengan menggunakan uji chi-square dalam tingkat kepercayaan 95\% ( $\alpha: 0,05)$ dan df: 2 diperoleh $\mathrm{X}^{2}$ hitung $(13,469)>\mathrm{X}^{2}$ tabel $(5,591)$, maka Ha diterima Ho ditolak sehingga ada Hubungan Motivasi Suami dengan Kepatuhan Kunjungan Ulang di Klinik Bidan N.Lumbangaol Desa Simangaronsang Kecamatan Doloksanggul Kabupaten Humbang Hasundutan Tahun 2018. 
Tabel 4. Distribusi Frekuensi Pengetahuan Responden Menurut Sumber Informasi Tentang Kepatuhan Kunjungan Ulang Di Klinik Bidan N. Lumbangaol Desa Simangaronsang Kecamatan Doloksanggul Kabupaten Humbang Hasundutan Tahun 2018

\begin{tabular}{|c|c|c|c|c|c|c|c|c|c|}
\hline \multirow[t]{3}{*}{ No } & \multirow[t]{3}{*}{ Sumber Informasi } & \multicolumn{6}{|c|}{ Kepatuhan kunjungan ulang } & \multirow[t]{3}{*}{ df } & \multirow[t]{3}{*}{$\mathbf{X}^{2}$} \\
\hline & & \multicolumn{2}{|c|}{ Patuh } & \multicolumn{2}{|c|}{ Tidak patuh } & \multicolumn{2}{|c|}{ Total } & & \\
\hline & & $\mathbf{n}$ & $\%$ & $\mathbf{n}$ & $\%$ & $\mathbf{N}$ & $\%$ & & \\
\hline 1 & Tenaga kesehatan & 30 & 83,33 & 6 & 16,67 & 36 & 100,0 & 2 & 8,028 \\
\hline 2 & Media elektronik & 16 & 80 & 4 & 20 & 20 & 100,0 & & \\
\hline 3 & Kurang & 0 & 0 & 2 & 100 & 2 & 100,0 & & \\
\hline
\end{tabular}

Berdasarkan tabel 4 diketahui bahwa dari 36 responden yang mendapatkan sumber informasi dari tenaga kesehatan mayoritas yang patuh 30 orang $(83,33 \%)$, dan minoritas yang tidak patuh sebanyak 6 orang $(16,67 \%)$. Dari 20 responden yang mendapatkan sumber informasi dari media elektronik mayoritas yang patuh 16 orang $(80 \%)$, dan minoritas sebanyak 4 orang $(20 \%)$. Dari 2 responden yang mendapat sumber informasi dari media cetak sebanyak 2 orang mayoritas yang tidak patuh sebanyak 2 orang (100\%).

Dengan menggunakan uji chi-square dalam tingkat kepercayaan 95\% ( $\alpha: 0,05)$ dan df: 2 diperoleh $\mathrm{X}^{2}$ hitung $(8,028)>\mathrm{X}^{2}$ tabel $(5,591)$, maka Ha diterima Ho ditolak sehingga ada Hubungan Sumber Informasi Dengan Kepatuhan Kunjungan Ulang Di Klinik Bidan N.Lumbangaol Desa Simangaronsang Kecamatan Doloksanggul Kabupaten Humbang Hasundutan Tahun 2018.

\subsection{Pembahasan}

Pengetahuan Akseptor KB Suntik Tentang Kepatuhan Kunjungan Ulang Di Klinik Bidan N.Lumbangaol Desa Simangaronsang Kecamatan Doloksanggul Kabupaten Humbang Hasundutan Tahun 2018

Berdasarkan hasil uji menggunakan uji chi-square dalam tingkat kepercayaan $95 \%(\alpha: 0,05)$ dan df: 2 diperoleh $\mathrm{X}^{2}$ hitung $(30,644)>\mathrm{X}^{2}$ tabel $(5,591)$, maka Ha diterima Ho ditolak sehingga ada Hubungan Pengetahuan Dengan Kepatuhan Kunjungan Ulang diketahui bahwa dari 58 responden ibu yang berpengetahuan baik sebanyak 36 orang (100\%) mayoritas patuh terhadap kunjungan sebanyak 32 orang $(88,9 \%)$ dan minoritas kategori tidak patuh sebanyak 4 orang $(11,11 \%)$. Pada pengetahuan ibu kategori Cukup sebanyak 15 orang dengan

Mayoritas patuh terhadap kunjungan ulang sebanyak 14 orang $(93,33 \%)$ dan minoritas tidak patuh sebanyak 1 orang $(6,67 \%)$. Dan pengetahuan kurang sebanyak 7 orang (100\%) semuanya tidak patuh terhadap kunjungan ulang KB suntik DMPA. Menurut Notoadmojo bahwa pengetahuan merupakan hasil dari tahu. Pengetahuan adalah sejumlah fakta teori yang memungkinkan seseorang untuk dapat memecahkan masalah yang dihadapi (Setiadi, 2007). Pengetahuan tersebut diperoleh baik dari pengalaman langsung maupun pengalaman orang lain.

Hasil penelitian ini sesuai dengan hasil penelitian yang dilakukan oleh (Desi D Hastuti, 2015) dengan judul hubungan pengetahuan tentang $\mathrm{KB}$ suntik 3 bulan dengan ketepatan kunjungan ulang pada akseptor KB di BPS Ny.Dini melani condong catur sleman Yogyakarta tahun 2015 dari 33 responden yang berpengetahuan baik sebanyak 17 orang $(51,1 \%)$ dan yang tepat melakukan kunjungan ulang sebanyak 22 orang $(66,7 \%)$ dengan menggunakan hasil uji Fisher's Exact Test.

Hasil analisi data bahwa dari 36 responden yang berpengetahuan baik sebanyak 36 orang dengan kepatuhan kunjungan ulang yang patuh melakukan kunjungan ulang sebanyak 32 orang (88,99\%). Hal ini dapat disebabkan Pengetahuna tersebut dapat diperoleh dari indra penglihatan dengan membaca buku, gambar, leaflet dan lain-lain. Dimana semakin tinggi tingkat pendidikan seseorang maka semankin tinggi pula tingkat pengetahuan seseorang.

Motivasi Suami Akseptor KB Suntik Tentang Kepatuhan Kunjungan Ulang Berdasarkan Motivasi Suami Di Klinik Bidan N. Lumbangaol Desa Simangaronsang Kecamatan Doloksanggul Kabupaten Humbang Hasundutan Tahun 2018

Dari hasil uji chi-square dalam tingkat kepercayaan 95\% ( $\alpha: 0,05)$ dan df: 2 diperoleh $\mathrm{X}^{2}$ hitung $(13,469)>X^{2}$ tabel $(5,591)$, maka Ha diterima Ho ditolak sehingga ada Hubungan Motivasi Suami Dengan Kepatuhan Kunjungan Ulang diketahui bahwa dari 58 responden yang motivasi suami kategori baik sebanyak 25 orang mayoritas patuh terhadap kunjungan ulang ibu sebanyak 23 orang (92\%) minoritas kategori tidak patuh sebanyak 2 orang (8\%). Pada motivasi kategori cukup sebanyak 26 orang terdapat mayoritas patuh sebanyak 21 orang $(80,77 \%)$ dan minoritas kategori tidak patuh sebanyak 5 orang $(19,23 \%)$. Dan motivasu suami yang kurang sebanayk 7 orang yang mayoritas kategori tidak patuh sebanyak 5 orang $(71,42 \%)$ dan minoritas patuh sebanyak $2(28,58 \%)$.

Motivasi adalah sebuah dorongan atau alasan yang mendasari semangat dalam melakukan sesuatu tetapi mempunyai arti penting dan mengerjakanya menjadi lebih baik (Adair, 2007). Perilaku manusia itu 
hakekatnya adalah berorientasi pada tujuan dengan kata lain bahwa perilaku seseorang itu pada umumnya diransang oleh keinginan untuk mencapai beberapa tujuan (Thuha, 2004).

Hasil penelitian ini sesuai dengan hasil penelitian Evi Luvia Cahyanidari 92 responden yang mendapatkan dukungan suami terhadap kepatuhan akseptor melakukan KB suntik yang baik sebanyak 60 responden $(65,2 \%)$, cukup 16 Responden $(17,4 \%)$ dan yang kurang $16(17,4 \%)$. Hasil ini menunjukan bahwa sebagian besar akseptor yang melakukan kujungan KB suntik di BPS Pipin Heriyanti sudah mendapatkan dukungan suami dengan katagori baik untuk melakukan kunjungan KB suntik.

\section{Pengetahuan Akseptor KB Suntik Tentang Kepatuhan Kunjungan Ulang Berdasarkan Sumber Informasi Di Klinik Bidan N.Lumbangaol Desa Simangaronsang Kecamatan Doloksanggul Kabupaten Humbang Hasundutan Tahun 2018.}

Bersadarkan tabel 3 menunjukkan bahwa dari 58 responden yang mendapatkan sumber informasi dari petugas kesehatan mayoritas yang patuh sebanyak 30 orang $(83,3 \%)$. Dan minoritas yang tidak patuh sebanyak 6 orang $(16,7 \%)$. Dari 20 responden yang mendapatkan sumber informasi dari Media elektronik mayoritas yang patuh melakukan kunjungan ulang sebanyak 16 orang (80,0\%), dan minoritas yang tidak patuh melakukan kunjungan ulang sebanyak 4 orang (20,0\%). Dari 2 reponden yang mendapatkan sumber informasi dari media cetak mayoritas yang tidak patuh melakukan kunjungan ulang sebanyak 2 orang $(100,0 \%)$. Dengan menggunakan uji chi-square dalam tingkat kepercayaan 95\% $(\alpha: 0,05)$ dan df: 2 diperoleh $\mathrm{X}^{2}$ hitung $(8,028)>\mathrm{X}^{2}$ tabel $(5,591)$, maka Ha diterima Ho ditolak sehingga ada Hubungan sumber motivasi dengan kepatuhan ibu diketahui bahwa dari 36 responden yang mendapatkan sumber informasi dari tenaga kesehatan mayoritas yang patuh 30 orang $(83,33 \%)$, dan minoritas yang tidak patuh sebanyak 6 orang (16,67\%). Dari 20 responden yang mendapatkan sumber informasi dari media elektronik mayoritas yang patuh 16 orang $(80 \%)$, dan minoritas sebanyak 4 orang $(20 \%)$. Dari 2 responden yang mendapat sumber informasi dari media cetak sebanyak 2 orang mayoritas yang tidak patuh sebanyak 2 orang (100\%). Sumber informasi merupakan alat atau saluran untuk menyampaikan informasi guna menambah wawasan. Media untuk menyalurkan informasi komunitas itu ada bermacam-macam seperti surat kabar, televisi, dan lain-lain (Notoatmodjo, 2010).

\section{CONCLUSION}

Dari hasil penelitian tentang Hubungan Pengetahuan Dan Motivasi Suami Ibu Akseptor KB Suntik DMPA Dengan Kepatuhan Kunjungan Ulang Di Klinik Bidan N.Lumbangaol Desa Simangaronsang Kecamatan Doloksanggul Kabupaten Humbang Hasundutan Tahun 2018 dapat ditarik kesimpulan sebagai berikut:

1. Dari 36 orang responden, presentase yang berpengetahuan baik sebanyak 36 orang responden , mayoritas yang patuh melakukan kunjungan ulang sebanyak 32 orang (88,9\%). Dan minoritas yang tidak patuh melakukan kunjungan ulang sebanyak 4 orang $(11,1 \%)$.

2. Dari 58 responden, presentase yang mendapatkan motivasi baik dan patuh melakukan kunjungan ulang dari suami sebanyak 23 orang $(92,0 \%)$. Dan minoritas yang tidak melakukan kunjungan ulang sebanyak 2 orang $(8,0 \%)$.

3. Dari 58 responden yang mendapatkan sumber informasi dari petugas kesehatan mayoritas yang patuh sebanyak 30 orang $(83,3 \%)$. Dan minoritas yang tidak patuh sebanyak 6 orang $(16,7 \%)$.

\section{REFERENCES}

Anggraini, Yeti \& Martini. 2017. Pelayaanan Keluarga Berencana. Yogyakarta: Rohima Press.

Desi . 2015. Hubungan Pengetahuan Tentang Kb Suntik 3 Bulan Dengan Ketepatan Jadwal Penyuntikan Ulang Pada Akseptor Kb Di Bps Ny. Dini Melani Condong Catur Sleman Yogyakarta.

Fitri Imelda. 2018. Nifas, Kontrasepsi Terkini \& Keluarga Berencana. Yogyakarta: Gosyen.

Glasier,Anna\& Gabbie, Alisa. 2006. Keluarga Berencana \& Kesehatan Reproduksi. Jakarta: EGC.

Nilawati, Sri., Dkk. 2014. Jurnal Hubungan Dukungan Suami Dengan Kepatuhan Akseptor Kb Suntik Progestin Melakukan Suntik Ulang Di Bpm Ny. Supiyah, Amd.Keb Desa Muntung Kecamatan Candiroto Kabupaten Temanggung.

Notoadmojo. 2012. Metologi Penelitian Kesehatan. Jakarta: Rineka Cipta.

Noviawati, Diah Setya Arum, \& Sujiyatini. 2011. Panduan Lengkap Pelayanan Kb Terkini. Yogyakarta: Nuha Offset.

Prof. Dr. Syaodih. 2010. Metode Penelitian Pendidikan. Bandung: Remaja Rosdakarya.

Profil Kesehatan Humbang Hasundutan Tahun 2015.

Purwoastuti Ending, Dkk. 2017. Panduan Materi Kesehatan Reproduksi \& Keluarga Berencana.. Yogyakarta: Pustaka Baru. 
Setyaningrum, Dkk. 2014. Pelayanan Keluarga Berencana \& Kesehatan Reproduksi. Jakarta: Trans Info Media.

Siregar, Nova Sontry, Elfrida Sihite \& Renta Tumanggor. 2013. Diklat Kesehatan Reproduksi Dan Keluarga Berencana. Doloksanggul: Akademi Kebidanan Kesehatan Baru.

Siregar, Nova Sontry, Mayes Simamora \& Helfrida Sihite. 2014. Pedoman Pembingbingan Dan Penulisan Karya Tulis Ilmiah. Doloksanggul: Akademi Kebidanan Kesehatan Baru.

Soekitjo, Notoatmodjo. 2010. Metologi Penelitian Kesehatan. Jakarta: RinekaCipta.

Widyastuti, Y., Ramawati, A. \& Purnama ningrum, Y.E. 2009. Kesehatan Reproduksi. Yogyakarta: Fitramaya.

\section{BIOGRAPHIES OF AUTHORS}

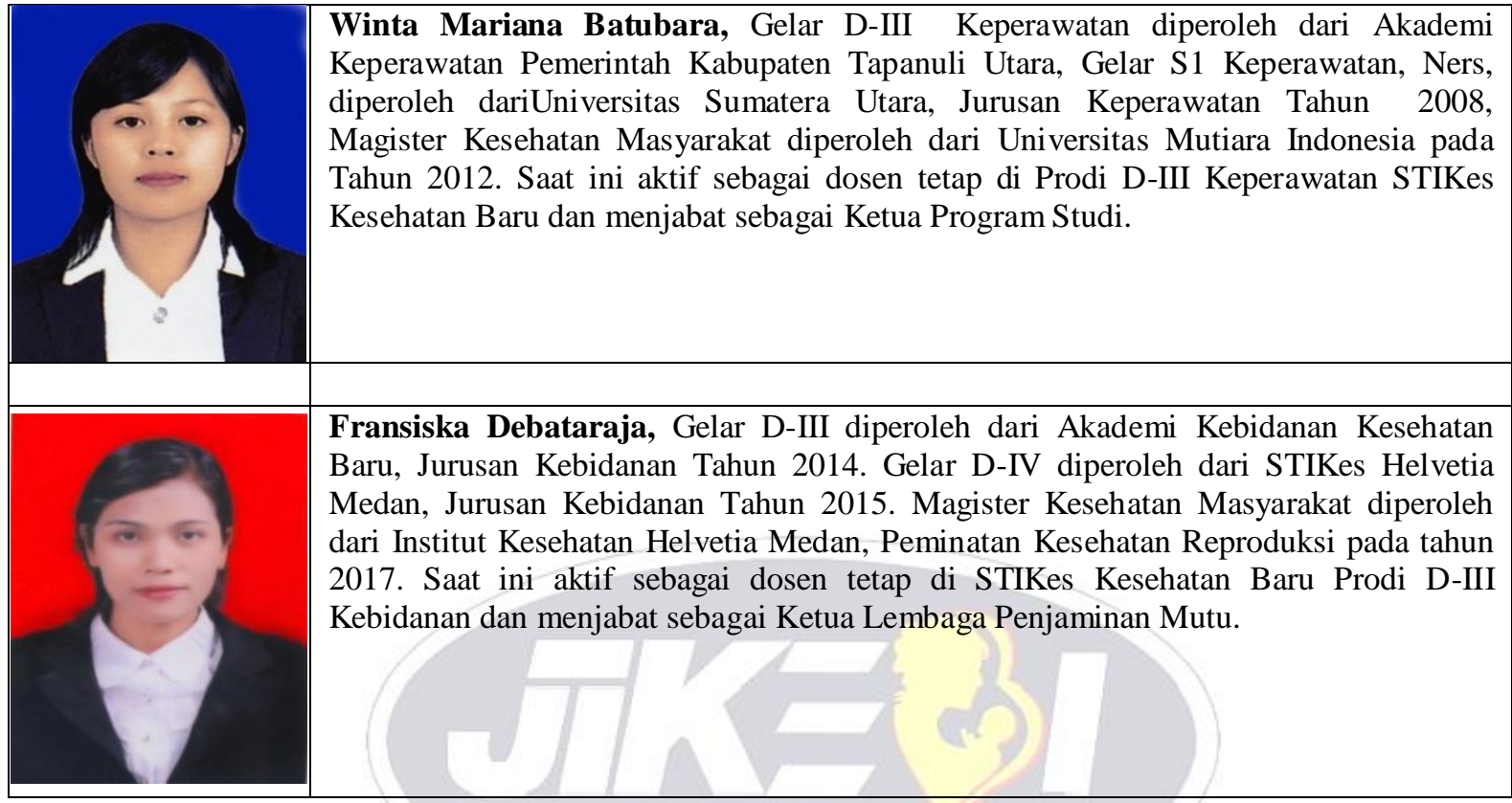

